\title{
The role of endoscopy and radiosurgery in the management of cavernous sinus meningiomas
}

\author{
Giulia Cossu' ${ }^{1}$, Javier Abarca ${ }^{2}$, Marc Levivier ${ }^{1}$, Daniele Starnoni ${ }^{1}$, Roy T. Daniel ${ }^{1}$, Moncef Berhouma ${ }^{3}$, \\ Mahmoud Messerer ${ }^{1}$ \\ 'Department of Neurosurgery, University Hospital of Lausanne, Lausanne 1011, Switzerland. \\ ${ }^{2}$ Department of Neurosurgery, University Hospital of Alicante, Alicante 03010, Spain. \\ ${ }^{3}$ Department of Neurosurgery, Pierre Wertheimer University Hospital. Hospices Civils de Lyon, Bron 69500, France.
}

Correspondence to: Dr. Giulia Cossu, Department of Neurosurgery, University Hospital of Lausanne, Rue du Bugnon 44, Lausanne 1011, Switzerland. E-mail: giulia.cossu@chuv.ch

\begin{abstract}
How to cite this article: Cossu G, Abarca J, Levivier M, Starnoni D, Daniel RT, Berhouma M, Messerer M. The role of endoscopy and radiosurgery in the management of cavernous sinus meningiomas. Mini-invasive Surg 2020;4:60.

http://dx.doi.org/10.20517/2574-1225.2020.52
\end{abstract}

Received: 26 May 2020 First Decision: 16 Jun 2020 Revised: 28 Jun 2020 Accepted: 8 Jul 2020 Published: 1 Sep 2020

Academic Editor: Oreste de Divitiis Copy Editor: Cai-Hong Wang Production Editor: Jing Yu

\begin{abstract}
Cavernous sinus (CS) meningiomas represent a formidable neurosurgical pathology. The desired treatment depends on tumor size and extensions apart from the presenting clinical symptoms of the patient. The last few decades have shown a paradigm shift in the management towards a multimodal treatment. For patients with tumors presenting with a medial extension or when the meningioma occupies the antero-inferior portion of the $\mathrm{CS}$, an endoscopic biopsy can be safely performed through the endonasal route. The boundaries of endoscopic endonasal approaches have been pushed during the last decade, and a direct access to the CS may now be performed. At the same time, an extensive bony decompression to decompress the optic canal and the pituitary gland may be performed. Autologous fat may be interposed between the residual tumor and radiosensitive structures to safely perform adjuvant radiation therapy. The aim of this manuscript is to describe the role of endoscopic surgery in the management of cavernous sinus meningiomas along with the complementary role of radiotherapy. We describe the endoscopic anatomy and the surgical technique to safely perform the procedure and we review the surgical series reported in the literature dealing with the endoscopic approach for CS meningiomas with or without complementary radiation therapy. Endoscopic endonasal approaches have shown promising results in terms of improvement or stabilization of cranial neuropathy and hypopituitarism. Furthermore, the endoscopic approach may enhance the efficacy and safety of stereotactic radiosurgery through the performance of an hypophysopexy and/or chiasmopexy.
\end{abstract}

\footnotetext{
(0) 0

(C) The Author(s) 2020. Open Access This article is licensed under a Creative Commons Attribution 4.0 International License (https://creativecommons.org/licenses/by/4.0/), which permits unrestricted use, sharing, adaptation, distribution and reproduction in any medium or format, for any purpose, even commercially, as long as you give appropriate credit to the original author(s) and the source, provide a link to the Creative Commons license, and indicate if changes were made.
}

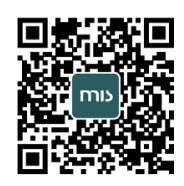


Keywords: Cavernous sinus, meningioma, skull base, surgery, endoscopy, radiosurgery, radiotherapy

\section{INTRODUCTION}

Meningiomas account for one third of primary intracranial tumors with an incidence of 3-8 per 100,000 persons ${ }^{[1]}$. They represent more than $40 \%$ of lesions involving the cavernous sinus $(\mathrm{CS})^{[2]}$. CS meningiomas originate or invade the parasellar space: they may start primarily within the CS or it may be involved secondarily in clinoidal or other sphenoid wing meningiomas, in addition to those arising from the tuberculum sellae or spheno-petro-clival region. CS meningiomas are deeply located near critical neurovascular structures such as the optic pathways, the hypothalamo-hypophyseal axis, the internal carotid artery and its branches, and the oculomotor and trigeminal nerves. They may further extend into the supra and latero-sellar spaces, orbital apex and optic canal, sphenoid ridge, middle temporal fossa, and petroclival angle. The CS region, due to its complex anatomy and its particular position in the antero-lateral skull base, has always been a challenging area of treatment for neurosurgeons.

As with the great majority of intracranial meningiomas, CS meningiomas are WHO grade I tumors with a very slow growing rate. Their surgical treatment may result in significant neurological morbidity and even death. For this reason, the management of these patients should be multidisciplinary discussed according to the size, extension, clinical presentation, and evolutive pattern to grant the patients the longest survival possible with the lowest cranial nerve morbidity.

Small and asymptomatic meningiomas are often managed conservatively ${ }^{[3]}$. In general, $15 \%$ of patients have neurological deficits at presentation ${ }^{[4,5]}$. Ophthalmoplegia, secondary to tumor growth or as a complication of treatment, can represent a serious issue that strongly impairs the quality of life of these patients, affecting their self-image and their private and professional life. Thus, a balance between the different therapeutic options should be found for symptomatic CS meningiomas. A complete preoperative endocrinological assessment and an ophthalmological evaluation should be performed for every patient with visual complaints and/or radiological compression of the optic apparatus.

Symptomatic meningiomas enclosed in the cavernous sinus are offered up front radiosurgery or stereotactic fractionated modality. Tumors presenting a lateral extension should be addressed through a transcranial approach for the resection of the extracavernous portion. In surgical series, recurrences and progression free-survival rates range from $6 \%$ to $25 \%$ and from $4.5 \%$ to $65 \%$, respectively, while the mortality rate varies between $2 \%$ and $7 \%$ and the morbidity from $10 \%$ to $65 \%{ }^{[6-8]}$. Thus, the results in terms of complete tumor removal, preservation of neurological functions, and quality of life do not always correspond to the expectations. Saberi et al. ${ }^{[9]}$ showed that the most important variable influencing the surgical outcome was the grade of encasement of nerves and vessels. The histological type, extent of dural attachment, and relationship and encasement with neurovascular structures should thus be carefully considered for the optimal management of CS meningiomas.

With CS meningiomas presenting a medial extension into the sphenoid sinus or extending into the antero-inferior portion of the CS, an endonasal approach can be performed as the tumor itself may create a safe space between the anterior dura and the internal carotid artery (ICA). Over the last few decades, endoscopic endonasalapproaches have remarkably developed with the development of extended approaches ${ }^{[10-14]}$. Through the transnasal route, it is possible to safely remove the tumor with a partial debulking, to decompress the optic canal or to perform a tissue biopsy when the diagnosis is not clear, particularly when another histological nature is suspected (lymphoma, granuloma, ectopic pituitary adenoma, neurofibroma, cavernous hemangioma, etc. $)^{[15-19]}$. The goals of endoscopic endonasal procedures 
Table 1. The advantages and disadvantages of the different surgical approaches for cavernous sinus meningiomas are here summarized

\begin{tabular}{|c|c|c|c|}
\hline & Transcranial surgery & Endoscopic surgery & Radiosurgery \\
\hline \multirow[t]{3}{*}{ PROS } & $\begin{array}{l}\text { To address the extracavernous portion of } \\
\text { the tumor in the temporal fossa }\end{array}$ & $\begin{array}{l}\text { Direct access for optic nerve and } \\
\text { pituitary gland decompression }\end{array}$ & Non-invasive procedure \\
\hline & $\begin{array}{l}\text { To address the supraclinoid portion of } \\
\text { the tumor lateral to the ICA or with an } \\
\text { encasement }\end{array}$ & $\begin{array}{l}\text { To avoid brain retraction and } \\
\text { manipulation }\end{array}$ & Low risk of complications \\
\hline & $\begin{array}{l}\text { To decompress the lateral portion of the } \\
\text { optic canal }\end{array}$ & $\begin{array}{l}\text { To interpose autograft fat to protect } \\
\text { radiosensitive structures (optic nerve } \\
\text { and pituitary gland) }\end{array}$ & $\begin{array}{l}\text { Good control rate (equivalent to Simpson } \\
\text { grade I) }\end{array}$ \\
\hline \multirow[t]{4}{*}{ CONS } & $\begin{array}{l}\text { High risk of cranial nerve palsy if the } \\
\text { lateral wall of the CS in entered }\end{array}$ & $\begin{array}{l}\text { Limited resection of the lateral portion of } \\
\text { the tumor }\end{array}$ & $\begin{array}{l}\text { Tumor too close to pituitary gland and } \\
\text { optic nerve are a relative contraindication }\end{array}$ \\
\hline & Risk of vascular injury & $\begin{array}{l}\text { Risk of vascular injury and of cranial } \\
\text { nerve palsy }\end{array}$ & No pathological analysis \\
\hline & $\begin{array}{l}\text { Risk of damage of brain parenchyma/ } \\
\text { epilepsy }\end{array}$ & Risk of hypopituitarism & Limited to small volumes \\
\hline & & Risk of CSF leakage & $\begin{array}{l}\text { No decompression, thus less chance to } \\
\text { improve pre-existing symptoms }\end{array}$ \\
\hline
\end{tabular}

CS: cavernous sinus; CSF: cerebrospinal fluid; ICA: internal carotid artery

are: (1) to perform an adequate bony decompression of the cavernous sinus, sella turcica and optic canal in cases with optic nerve compression; (2) to obtain tissue for a pathological analysis and a genomic profiling; (3) to reduce the volume of tumor to be treated by radiosurgery; and (4) to perform an hypophysopexy or chiasmapexy and allow a safer irradiation at a later date.

In most cases, the combination of a less aggressive surgical approach with a complementary radiation treatment seems to be the best management ${ }^{[20,21]}$. Indeed, aggressive surgical resections are associated with a higher risk of complications and do not improve the natural history of the disease or the global outcome except in carefully selected cases ${ }^{[2,23]}$ [Table 1]. Furthermore, many of these tumors tend to recur over the long term. The combined treatment should be realized in tertiary care centers with a large experience in this area and a sufficient caseload [Figure 1].

Herein, we detail the relevant endoscopic endonasal anatomy of the cavernous sinus region and review the results of the surgical series reported in the literature dealing with the endoscopic endonasal management of CS meningiomas.

\section{ENDOSCOPIC ANATOMY}

The cavernous sinus is a paired venous sinus surrounded by dural layers and located in the middle cranial fossa. It is limited medially by the sphenoid bone and the sellar region, and laterally by the mesial face of the temporal lobe. The posterior margin is limited by the posterior cranial fossa, while anteriorly the cavernous sinus reaches the superior orbital fissure and the inferior surface of the anterior clinoid process. Cavernous sinus floor extends from the anterior to the posterior clinoid process and faces the basal cisterns. The lateral dural wall of the cavernous sinus is composed of the outer dural layer and the inner membranous layer. The inner layer contains the most critical nervous structures. The existence of a medial dural wall separating the pituitary from the CS remains a matter of debate ${ }^{[24]}$. The CS contains multiple neurovascular structures: the sympathetic plexus around the internal carotid artery, the oculomotor nerves (III, IV, and VI) and the first and second roots of the trigeminal nerve (V1 and V2). In a cranio-caudal direction the III, IV, V1, and V2 course within the lateral wall of the sinus, while the VI cranial nerve is positioned within the CS, just lateral to the ICA [Figures 2 and 3].

To reach the CS through an endoscopic endonasal corridor, the extent of the approach varies from a standard transsphenoidal approach to more extended accesses, which include transpterygoid approaches 


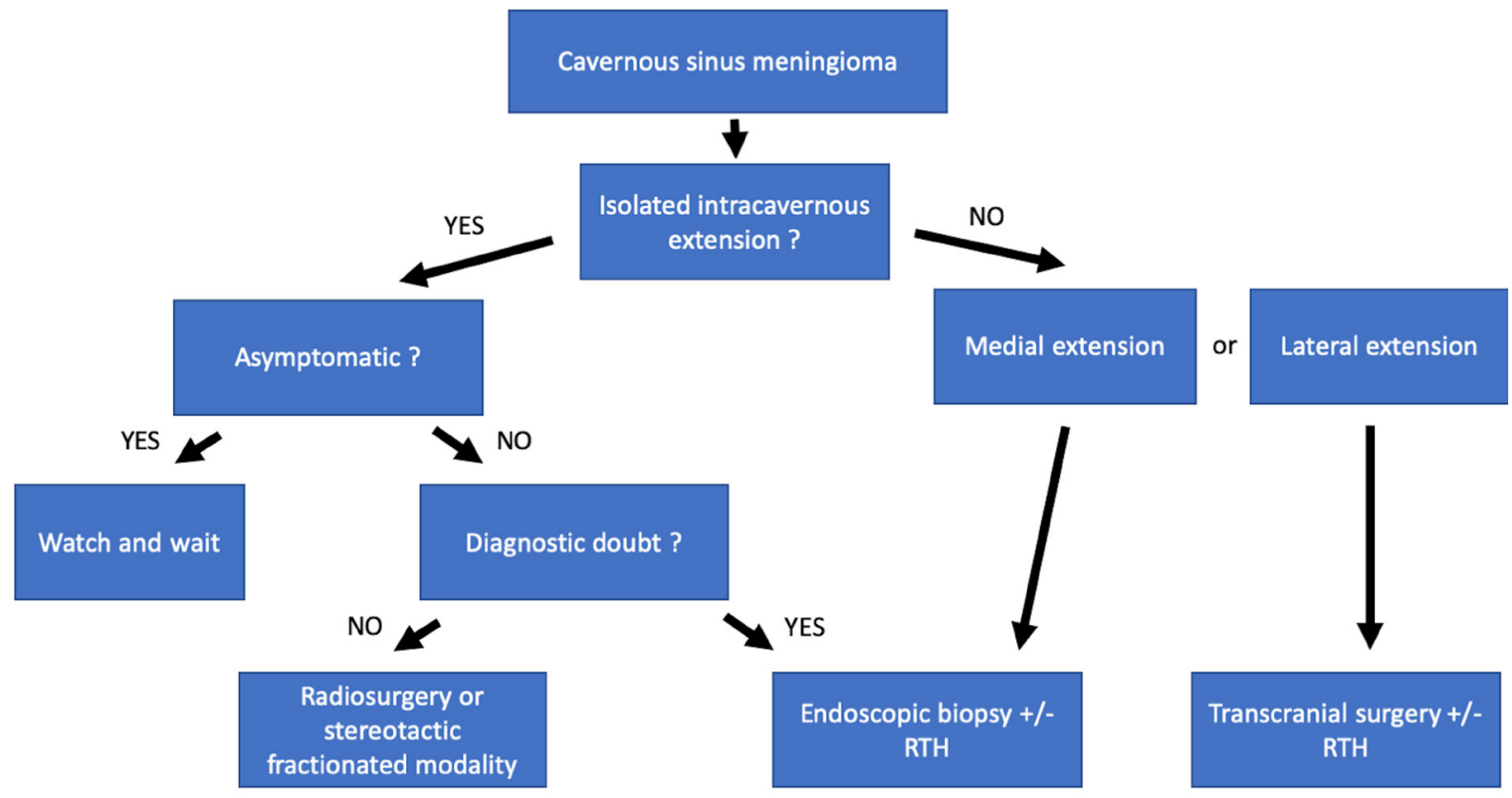

Figure 1. Algorithm showing the management of patients with cavernous sinus meningiomas according to the extension of the tumor and the clinical presentation or the doubt on the histological diagnosis. RTH: radiation therapy

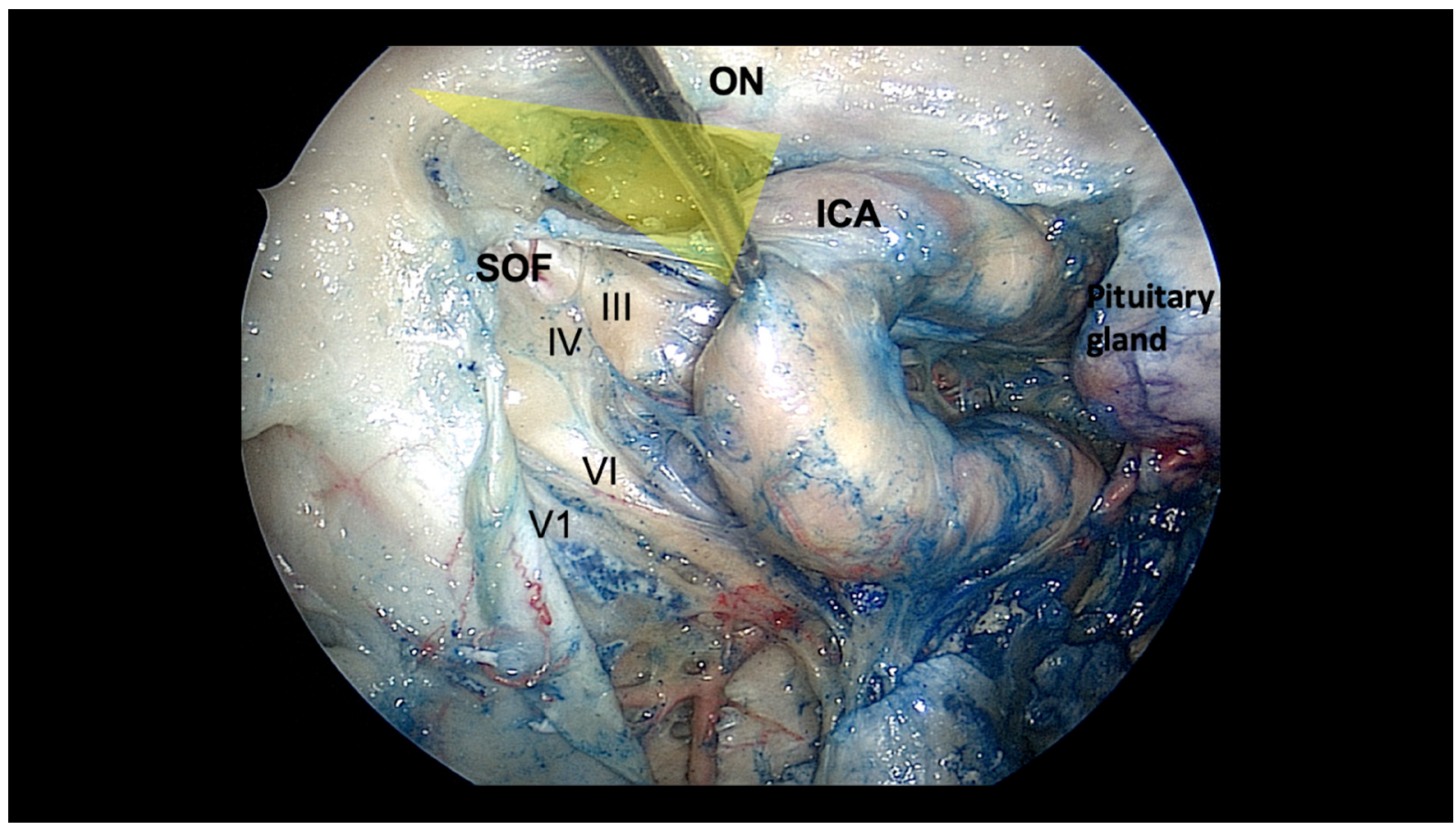

Figure 2. Endoscopic endonasal view of the right CS in a cadaveric specimen. The bone covering the CS was completely drilled to expose the ICA, the oculomotor nerves (III, IV, and VI) going to the SOF, and the first branch of the trigeminal nerve (V1). Superiorly, the $\mathrm{ON}$ is still covered by a thin layer of bone. The lateral optico-carotid recess is colored in yellow. Medially, the pituitary gland is also exposed. CS: cavernous sinus; ICA: internal carotid artery; ON: optic nerve; SOF: superior orbital fissure

with anterior and posterior ethmoidectomies and vidian canal dissection. The anatomy of the sphenoid sinus in terms of pneumatization and presence of septa should be carefully considered on preoperative imaging. The sphenopalatine artery courses at the inferior portion of the sphenoid ostium and should 


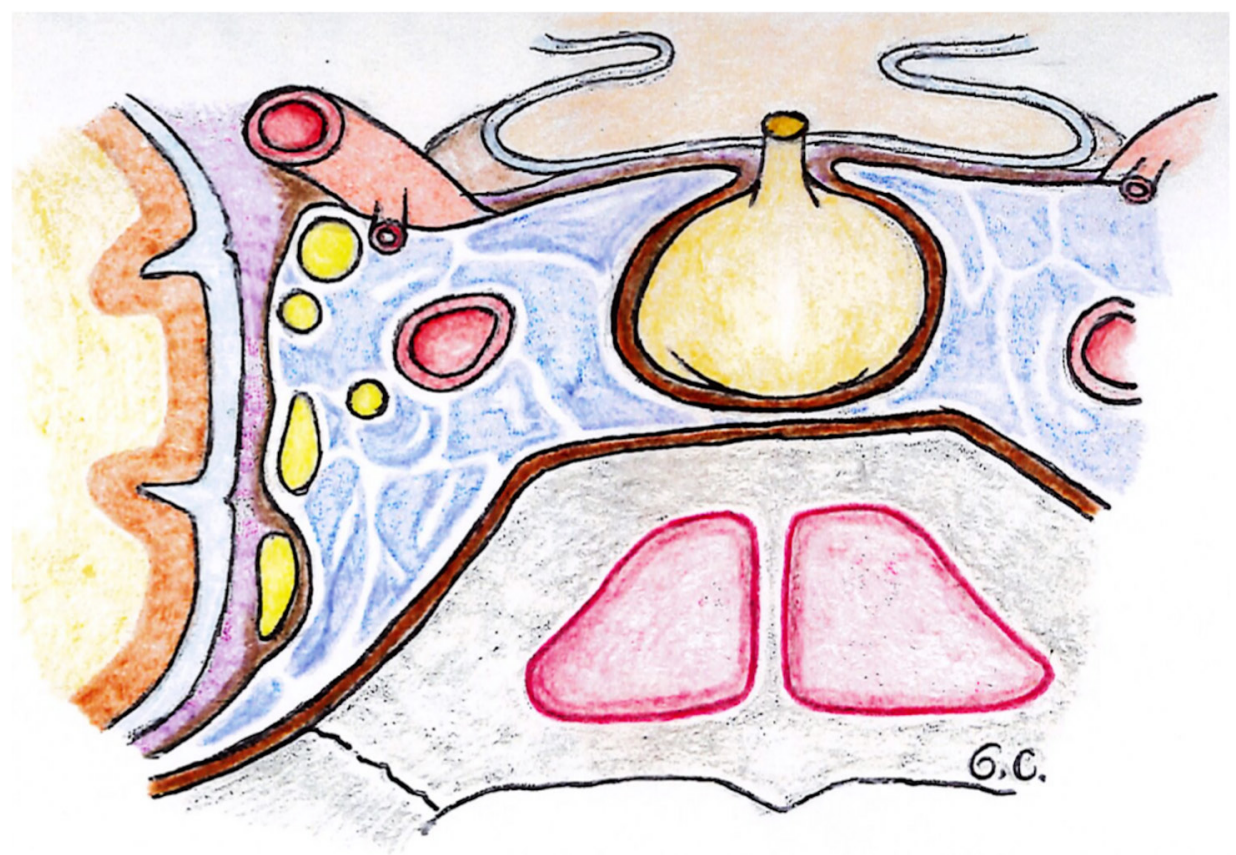

Figure 3. Schematic representation of the right cavernous sinus. The III, IV, V1, and V2 course within the lateral wall of the sinus in a craniocaudal order, while the VI cranial nerve is the only one inside the cavernous sinus, just lateral to the internal carotid artery

be preserved. Once the sphenoid sinus is entered, the sellar floor is identified in the midline with the tuberculum sellae and the landforms of the optic canals superiorly and laterally, as well as the carotid prominences laterally. The medial and lateral optico-carotid recesses are also recognized [Figure 4] ${ }^{[25]}$. Within the sphenoid sinus, the anterior CS corresponds to the anterior carotid prominence, easily identified on the lateral sphenoid sinus wall.

In cases where a transpterygoid approach is performed, the bony anatomy of the maxillary and ethmoid sinuses should be analyzed. The pterygopalatine fossa is a pyramidal space located between the pterygoid bone posteriorly, the palatine bone anteromedially, and the maxillary bone anterolaterally ${ }^{[10,11]}$. Once the maxillary sinus is entered, the infraorbital nerve is a consistent landmark and the pterygopalatine fossa is medial to it. It has a rich vasculonervous content, namely the third segment of the maxillary artery and its branches (anterior compartment of the fossa) [Figure 5], the pterygopalatine ganglion, the greater and lesser palatine nerves, the maxillary and infraorbital nerves, and the vidian nerve (posterior compartment) ${ }^{[10-14]}$. The anterior opening of the vidian canal is located medially while the foramen rotundum is located laterally ${ }^{[10]}$. Foramen lacerum and petrous ICA may be exposed following the vidian nerve posteromedially, while the lateral portion of the clival recess is the landmark for the medial wall of the paraclival ICA. The foramen rotundum can also be used as an anatomical landmark for the antero-inferior wall of the CS during extended approaches.

\section{IMAGING}

Both CT-Scan and MRI are essential to assess the bony and neurovascular relationships of the meningioma. MRI shows the exact location and the extension of the meningioma. It helps in defining the limits of the tumor in relationship with the neurovascular structures inside and outside the CS. T2-weighted coronal sequences allow a good analysis of the meningioma's relationships with the CS dural layers [Figure 6]. The distance from the optic pathways, the cranial nerves anatomy, and the pituitary region can also be carefully appraised particularly using CISS-3D or FIESTA sequences as well as cranial nerve tractography. 


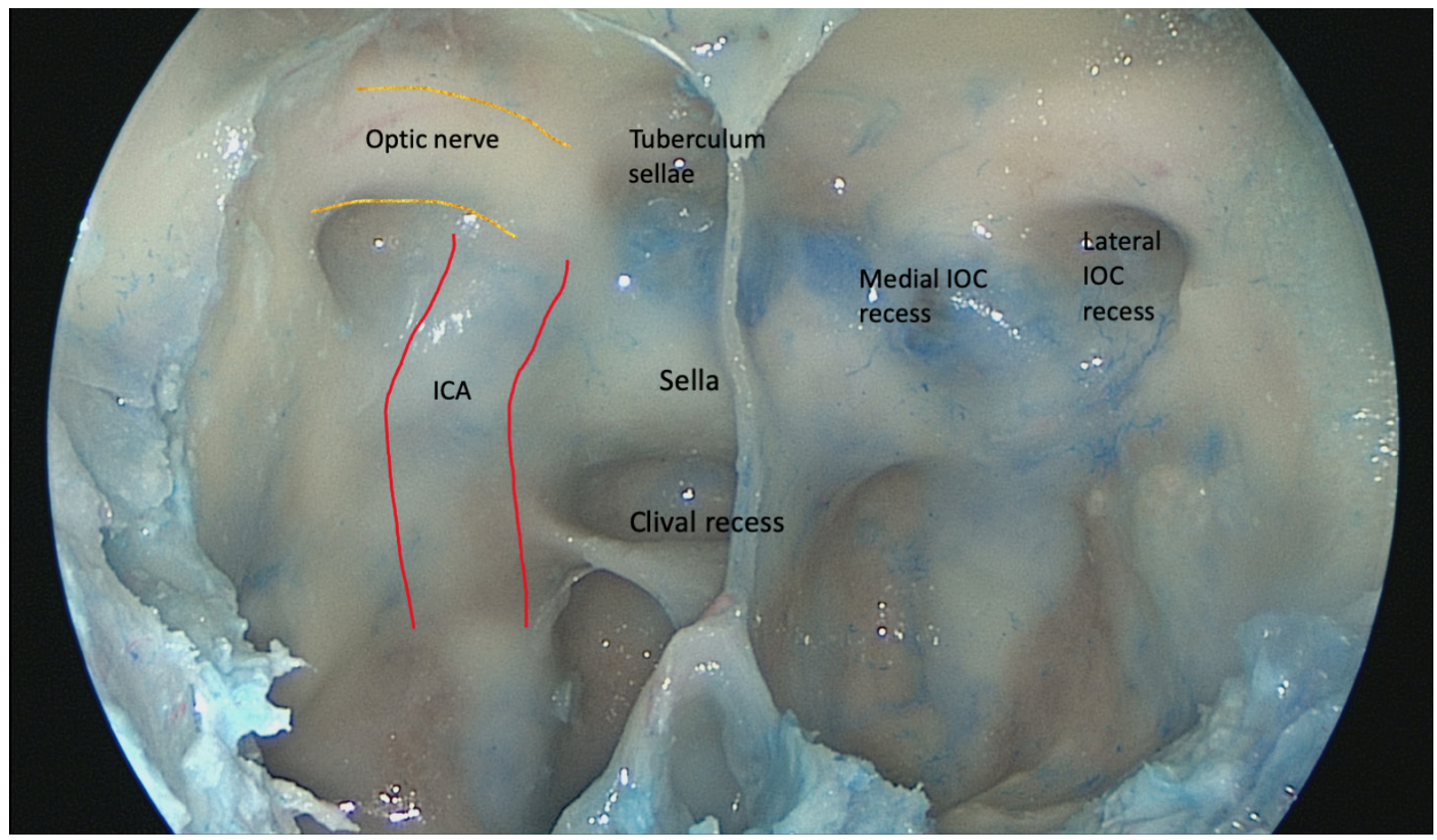

Figure 4. Endoscopic endonasal view of the posterior wall of the sphenoid sinus in a cadaveric specimen. A midline septum was partially drilled. In the midline, in a craniocaudal direction, the tuberculum sellae, the sella, and the clival recess are evident. Laterally, the carotid prominence (red lines) and, superiorly, the optic nerve (golden lines) are delimited. The medial and lateral IOC recesses are also marked. ICA: internal carotid artery; IOC: interoptico-carotid

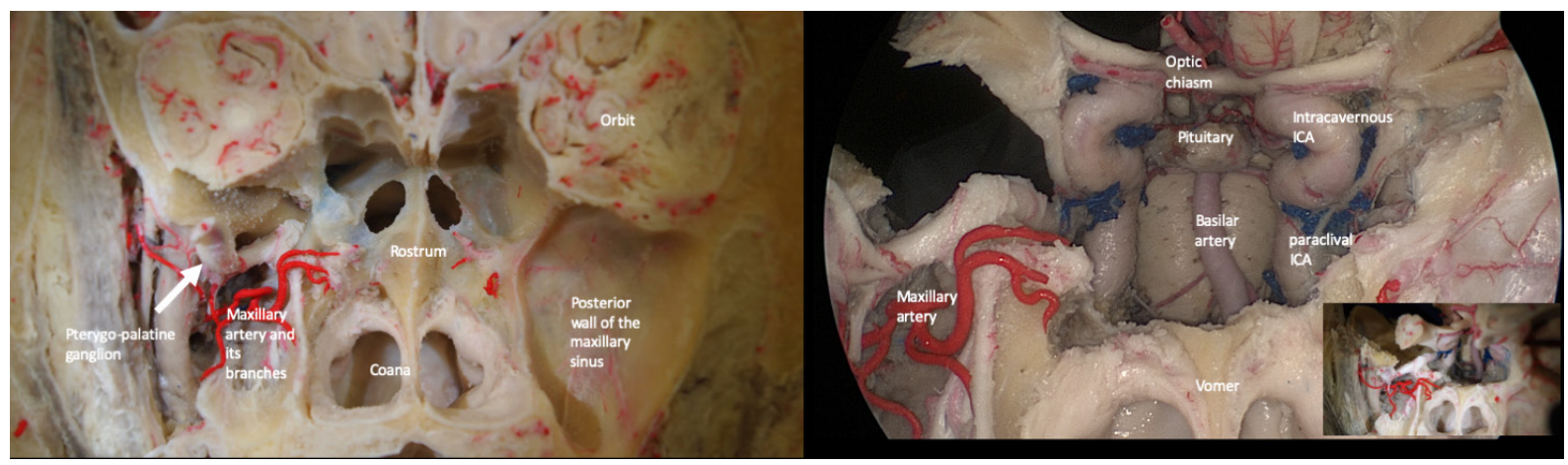

Figure 5. Coronal view of the pterygo-palatine fossa in a cadaveric specimen. Once that the posterior wall of the maxillary sinus is opened, the maxillary artery and the pterygopalatine ganglion are exposed (left). A large sphenoidotomy is performed to illustrate the close relationships between the different structures. Once that the vidian nerve is identified, it can be followed posteriorly until the foramen lacerum and the petrous ICA (right). ICA: internal carotid artery

High-resolution contrast-enhanced axial MRI is necessary in the preoperative planning and fat suppression images may be used for tumors adjacent to the orbit or when a chiasmapexy has been previously performed. The angio-MRI is useful to delineate the caliber and the displacement of the ICA and its branches, while the MR-venography illustrates the venous drainage of the skull base ${ }^{[26]}$. A detailed study of the ICA course and of the collateral systems is fundamental before starting the resection of a CS meningioma.

Thin-slices bone CT scan is valuable to study the presence and direction of septa and the degree of pneumatization of the sphenoid sinus, the anatomy of the anterior and posterior clinoid processes, the sella turcica and the orbital apex, the sphenoid wing and its foramina, and the petrous apex. The invasion of 


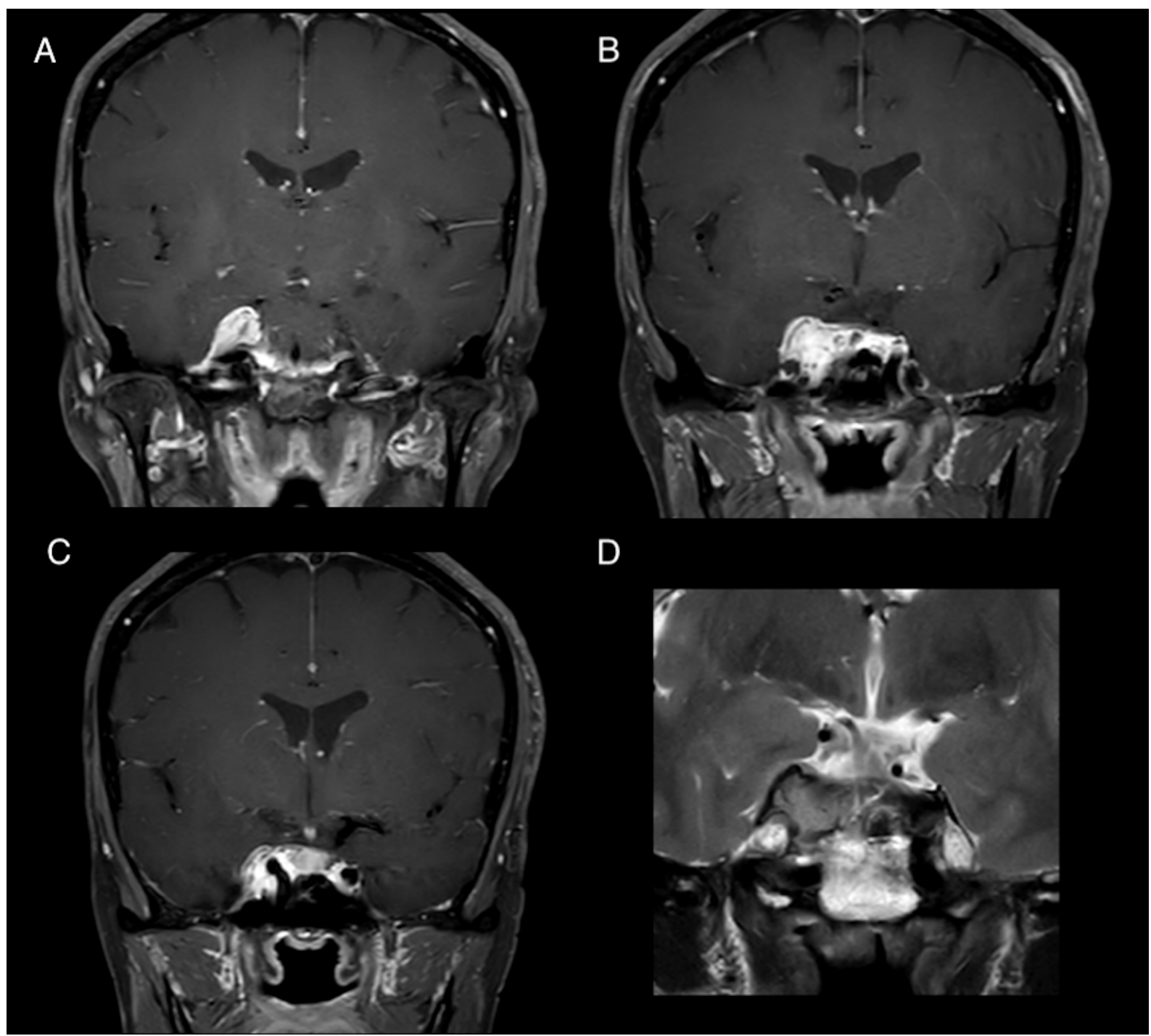

Figure 6. Coronal view of a cerebral MRI showing a meningioma in the right CS. The asymmetry between the row cavernous sinuses is evident and the lesion present a strong contrast enhancement after gadolinium administration (A-C). The relationships between the meningioma and the lateral wall of the CS and the optic apparatus are better defined through the analysis of T2-weighted sequences (D). CS: cavernous sinus

the optic canal and the superior orbital fissure, as well as rotundum, ovale, and lacerum foramina, should be checked for, as well as the potential invasion of the sphenoid sinus. The presence of osteolysis or bone reactive hypertrophy should be carefully evaluated. The latter in particular could reflect tumoral infiltration and may be the target for extensive drilling.

While angio-MRI and angio-CT have progressively lessened the need for digital subtraction angiography, this may be useful to evaluate the collateral network, particularly in case of ICA narrowing using balloon occlusion tests.

\section{SURGICAL TECHNIQUE}

The endonasal approach to address CS meningiomas has the advantage of avoiding brain retraction and manipulation, with a straightforward access to decompress the optic nerve, pituitary gland, and cranial nerves. The endoscope allows a panoramic visualization and a more lateral exposure when compared to 
microscopic endonasal approaches ${ }^{[27]}$. This permits the performance of a precise bony decompression around the sella, the medial cavernous sinus, the optic canal, and, if necessary, of the clivus and Meckel's $\operatorname{cave}^{[17]}$. Furthermore, this approach allows the positioning of autograft fat between the tumor and radiosensitive structures for further treatments ${ }^{[28]}$.

After induction of general anesthesia, the endotracheal tube is positioned on the left of the patient and the head should be slightly tilted to the left, turned to the right, and slightly flexed as for a standard endoscopic endonasal transsphenoidal approach. The neuronavigation system is positioned to guide the procedure and the volumetric MRI is fused with the bone-window CT to increase the precision of target definition. Intraoperative monitoring is useful to monitor the function of the oculomotor and trigeminal nerves. The face, the right periumbilical area, and/or the thigh are draped for graft harvesting if necessary.

In general, a binostril bimanual technique is preferred to obtain a wider range of movement. The primary surgeon operates with dissecting instruments and the drill from the right nostril, while the assistant surgeon manages the endoscope in the right nostril and the suction in the left nostril to keep the surgical field clear. Alternatively, a contralateral uninostril approach can also be an option. The right middle turbinate can be resected to widen access if needed during the procedure. Once the sphenoid ostium is identified medial to the superior turbinate and superior to the choana, a wide sphenoidotomy is performed with a posterior septostomy. A large exposition of the sphenoid sinus is necessary to identify the posterior wall landmarks, including the tuberculum, sellar floor, and clival recess in the midline, as well as the optic canals, carotid prominences, and optico-carotid recesses laterally.

A key part of the procedure is bony decompression of the sella, cavernous sinus, optic canal superiorly, and upper clivus when necessary. The bone is generally removed with a high-speed diamond burr and the ultimate eggshell layer is removed with a Kerrison rongeur to safely expose the dura. Constant irrigation should be performed during the drilling to avoid thermic lesions to delicate neuro-vascular structures. The medial and the anterior wall of the cavernous sinus are exposed after the ipsilateral side of the sella is exposed. The medial optico-carotid recess is then progressively exposed. The optic canal unroofing is one of the most important steps, which should be carefully performed as this could induce visual deterioration ${ }^{[29]}$. This part of the procedure is necessary when there is a reduction in the caliber of the optic canal and/or when the patient presents with an optic neuropathy. Doppler ultrasound and neuronavigation are useful to localize the ICA during the osseous decompression and before dural opening. Tumor removal should be performed selectively with the goal of decompressing the optic nerve, the pituitary gland, and the cranial nerves into the cavernous sinus. The medial portion of the tumor invading the sella should be initially removed [Figure 7].

Subsequently, the dura over the cavernous sinus can be opened in a lateral to medial direction to avoid injury of the ICA. Brisk venous bleeding is common after tumor removal and can be controlled with hemostatic agents and temporary mechanical packing. A nerve stimulator is used to localize the course of VI cranial nerve once the CS is entered. Visualization of cranial nerves is not necessary and often dangerous. Electrocautery in the area should be avoided to prevent thermal injuries. Excision of the tumor is done in a piecemeal fashion with curettes and ultrasonic aspiration (particularly useful with fibrous tumors). The integrity of the lateral wall and the roof of the cavernous sinus should be respected. At the end of the resection, a hypophysopexy is performed with the positioning of small pieces of fat between the residual tumor and the pituitary gland to fill the dead space created by tumor removal and to better delineate the target and provide a margin for adjuvant radiosurgery in order to protect radiosensitive structures. In general, when a biopsy is performed for purely intracavernous lesions, there is no CSF leakage. An artificial dural substitute or fascia lata from the thigh and glue are sufficient for skull base reconstruction. A nasoseptal flap is rarely required. An endocrinological assessment should be performed in the postoperative period and records are kept for fluid intake and urine output. 


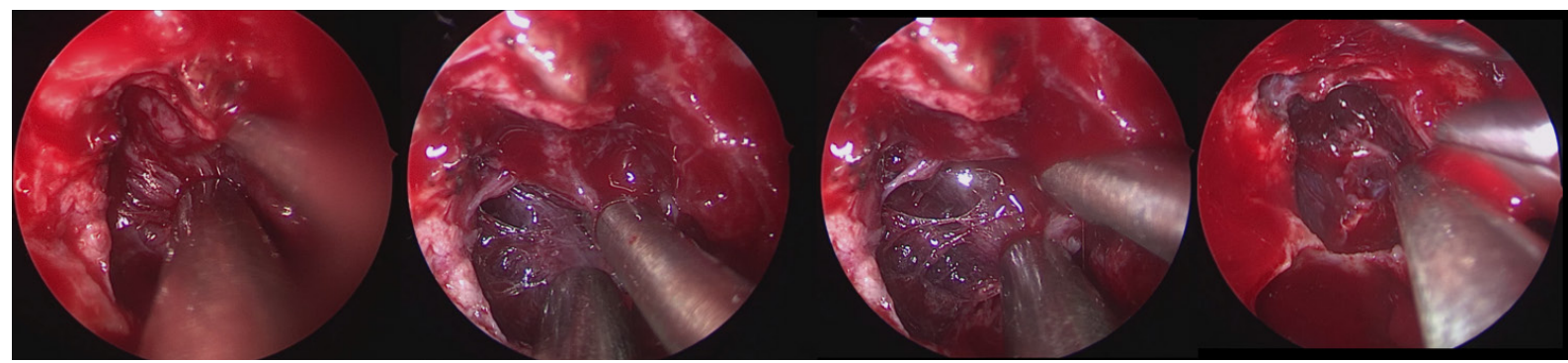

Figure 7. Intraoperative pictures showing the endoscopic resection of an infradiaphragmatic meningioma invading the right cavernous sinus. The resection should start from the intrasellar portion and then proceed towards the cavernous sinus. A complete removal of the meningioma invading the medial portion of the cavernous sinus was possible in this case

\section{REVIEW OF REPORTED SURGICAL SERIES}

We performed a literature review on PubMed database up to April 2020 to summarize the surgical series treating patients with CS meningiomas through endoscopic surgery followed or not by adjuvant radiotherapy. The articles were identified using Boolean searches with the keywords "endoscopy" AND "cavernous sinus" AND "meningioma". Table 2 shows in detail the surgical results and the final outcome. Nine series published between 2009 and 2020 gathered 106 patients in whom an endoscopic endonasal approach was performed for CS meningiomas ${ }^{[18,28,30-36]}$. In most of cases, the aim was to perform a tissue biopsy and decompression of cranial nerves in the CS or optic nerve. gross total resection was performed only in rare cases ${ }^{[18,33-35]}$.

In only nine cases (8.5\%), a worsening of the cranial nerve palsy was recorded, while in three out of 97 cases (3\%) a new endocrinological deficit occurred. The surgical complications reported were: CSF leakage in three cases, one case needed a ventriculoperitoneal shunt but he was operated through a combined approach (endoscopic and transcranial), and two patients experienced an ICA injury (one died from a hemispheric infarct). Forty-three out of 64 patients (67\%) reported an improvement in CN palsy in the postoperative period and 22/41 (53.6\%) had an improvement in their pituitary function. Adjuvant radiation therapy was administered in $43 / 78$ patients (55\%). The protocols of radiation therapy administered varied from stereotactic radiotherapy (RT) to radiosurgery or particle beam irradiation and when specified the tumor control was excellent at a mean follow-up of 39 months. Only one complication of stereotactic RT was reported with the development of a pituitary insufficiency after the treatment.

Endoscopy might enhance the efficacy and safety of stereotactic radiotherapy or radiosurgery. This might be due to the fact that during surgery an adequate distance can be created between the tumor and the pituitary through the resection of the meningioma, thus allowing a safer irradiation. Furthermore, the interposition of abdominal fat (hypophysopexy) between the meningioma and the pituitary gland may limit the risk of post-radiation endocrinopathies.

In summary, from these studies, we can conclude that a biopsy or planned partial tumor removal may be safely performed, coupled with bony decompression, to improve the visual symptoms and obtain a decompression of the cavernous sinus. Better results in terms of symptomatic improvement were obtained in the cohort of previously untreated patients ${ }^{[28]}$.

Furthermore, endoscopy may improve or stabilize pre-existent cranial neuropathy and endocrinopathy (67\% of patients in Lobo's series improved their endocrinopathy and $42 \%$ of patient improved or resolved their cranial neuropathy $)^{[32]}$. 


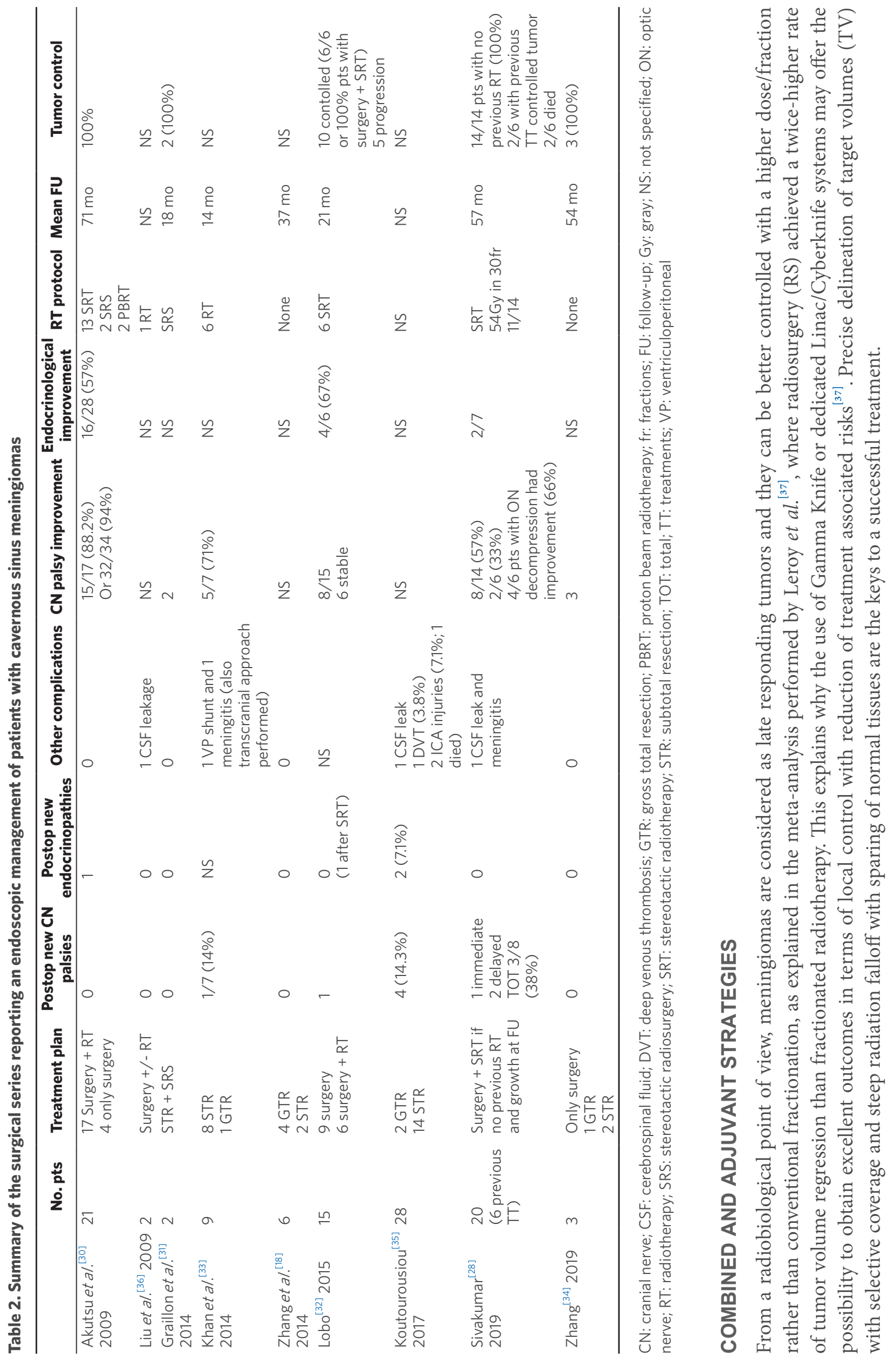


RS can be considered as first line treatment for small symptomatic CS meningiomas if they present a safe distance from the optic pathway ${ }^{[38-43]}$. For large meningiomas, a single fraction RS may be problematic as the risk of damaging healthy tissues is high and a complication rate of $21 \% v s$. $3 \%$ was reported for meningiomas larger than $10 \mathrm{~cm}^{3} v s$. smaller lesions respectively ${ }^{[4]}$. Furthermore, the distance between the optic apparatus and the tumor should be carefully considered before choosing the primary treatment: a distance of at least $5 \mathrm{~mm}$ between the meningioma and the optic nerve is considered safe ${ }^{[45,46]}$. Thus, when the meningioma is large or too close to the optic pathways, a combined approach with a surgical partial decompression followed by adjuvant radiation therapy should be preferred.

Whether RS should be routinely performed in the months after surgery or only in cases of postoperative tumor progression is still a matter of debate. Considering the natural history of meningiomas, we know that they have a slow tendency to grow but about one fourth of all the meningiomas, in particular those calcified, do not seem to grow ${ }^{[47]}$. In common practice, the irradiation is generally performed $3-6$ months after surgery, while, for minimal residual tumors, radiation is performed when a growth is visible on follow-up images. This waiting time should help in the recovery of cranial nerves and pituitary gland surgical manipulation ${ }^{[32]}$. For atypical meningiomas or meningiomas showing an aggressive behavior with a higher growth rate, radiotherapy should be performed in a shorter period of time ${ }^{[32]}$. Beside the histological grade, the previous treatments performed should also be taken into account before planning the treatment. The inclusion of the dural tail in the TV is matter of debate, and, when an irregular shape is present, the dose distribution should be accurately checked ${ }^{[48-50]}$.

For radiosurgical treatments, the dose recommended is between 12 and $15 \mathrm{~Gy}$, which allows a good compromise between tumor growth control and local neurotoxicity. The risk of damaging the optic apparatus exists when the dose (to nerve) received is more than $8 \mathrm{~Gy}$. The oculomotor nerve in the cavernous sinus tolerates doses greater than 20 Gy while the trigeminal nerve is at risk with doses beyond 19 Gy. However, in common practice, the lateral wall of the cavernous sinus, the pituitary gland, and stalk, the hypothalamus and brainstem should not receive more than $15 \mathrm{~Gy}$.

In their review of the outcomes of large radiosurgical series, Fariselli et al. ${ }^{[1]}$ showed progression free survival at 5 and 10 years of $80 \%-100 \%$ and $73 \%-98 \%$, respectively, and a radiological volume reduction was observed in $29-69 \%$ of cases. No mortality was described as secondary to radiation therapy, while the reported morbidity included new neurologic symptoms or symptoms of neurotoxicity (optic neuropathy, pituitary dysfunction, diplopia, and radiation-induced edema), which ranged from $6 \%$ to $27.5 \%{ }^{\left[{ }^{[2-55]}\right.}$. A meta-analysis comparing primary RS $v s$. surgery followed by adjuvant RS showed a lesser rate of neurological morbidity in the primary RS group $(27.5 \% \text { vs. } 59.6 \%)^{[55]}$. Kano et al. ${ }^{[56]}$ reported that improvement in cranial nerve palsies was less likely to occur in patients who had undergone previous surgery when compared to those treated with radiosurgery alone ( $14 \% v s .39 \%)$. One explanation may be that operated patients had permanently damaged cranial nerves as a result of the surgery. It is well described that about $75 \%$ of recurrences occur outside the treatment field and this reflects the paramount importance that needs to be placed on the contouring phase of the treatment ${ }^{[57]}$.

For recurrent meningiomas, data on the efficacy of repeated RS are limited. Mifepristone and bevacizumab have been described as promising agents for recurrent tumors, but these results still need to be validated in larger studies. Nonetheless, these drugs, which target tumor receptors, highlight the importance of obtaining a histological diagnosis and genomic profiling before their introduction to select effective targeted therapies ${ }^{[58,59]}$.

\section{CONCLUSION}

The management of CS meningiomas depends on the size and extension of the tumor and on the clinical manifestations of the patient. The treatment decision varies among a simple annual clinico-radiological 
follow-up, transcranial or endoscopic surgery according to the extension of the tumor, radiation therapy, or the combination of both. The main goal of the treatment is to prevent growth and to avoid or prevent neurological deficits. For symptomatic meningiomas extending into the antero-inferior portion of the cavernous sinus, a direct endoscopic transcavernous approach should be preferred. It represents a safe procedure, with a very low complication rate when patients are carefully selected in a tertiary level center, with good improvement rates or at least stabilization of cranial neuropathies and endocrinopathy. Multidisciplinary recommendations for a specific treatment carries an important ethical responsibility and it is the duty of each surgeon to propose the best management to each patient keeping in mind the riskbenefit analysis.

\section{TRICKS}

1. An endoscopic transcavernous biopsy/partial removal is easily performed when the meningioma is located in the antero-inferior portion of the CS.

2. Intraoperative neuronavigation and careful understanding of preoperative anatomy are key factors in safely performing the procedure.

3. Fully endoscopic procedures should be preferred to microscopic procedures performed under endoscopic assistance for the better panoramic view allowed by the endoscope.

4. Doppler ultrasound is invaluable in localizing the carotid artery inside the tumor and guide tumor removal.

5. Bony decompression of the optic canal is a key step of the procedure to increase the chance of visual improvement.

6. Autologous fat can be interposed between the residual tumor and the pituitary gland to limit the risks of hypopituitarism after adjuvant radiation therapy.

7. A careful reconstruction should be performed to avoid postoperative CSF leakage.

8. Meningiomas better respond to higher dose/fraction of radiation therapy, and a gamma knife/ Cyberknife/Linac treatment should be preferred.

\section{DECLARATIONS}

\section{Authors' contributions}

Made substantial contributions to conception and design of the study and performed data analysis: Cossu G, Berhouma M, Messerer M

Performed data acquisition, as well as provided administrative, technical, and material support: Abarca J, Levivier M, Starnoni D, Daniel RT

\section{Availability of data and materials}

Not applicable.

\section{Financial support and sponsorship}

None.

\section{Conflicts of interest}

All authors declared that there are no conflicts of interest.

\section{Ethical approval and consent to participate}

Not applicable.

\section{Consent for publication}

Not applicable. 


\section{Copyright}

(c) The Author(s) 2020.

\section{REFERENCES}

1. Ostrom QT, Gittleman H, Xu J, Kromer C, Wolinsky Y, et al. CBTRUS Statistical Report: Primary Brain and Other Central Nervous System Tumors Diagnosed in the United States in 2009-2013. Neuro Oncol 2016;18:v1-75.

2. Radhakrishnan K, Mokri B, Parisi JE, O'Fallon WM, Sunku J, et al. The trends in incidence of primary brain tumors in the population of Rochester, Minnesota. Ann Neurol 1995;37:67-73.

3. Klinger DR, Flores BC, Lewis JJ, Barnett SL. The treatment of cavernous sinus meningiomas: evolution of a modern approach. Neurosurg Focus 2013;35:E8.

4. Pichierri A, Santoro A, Raco A, Paolini S, Cantore G, et al. Cavernous sinus meningiomas: retrospective analysis and proposal of a treatment algorithm. Neurosurgery 2009;64:1090-9; discussion 1099-101.

5. Maruyama K, Shin M, Kurita H, Kawahara N, Morita A, et al. Proposed treatment strategy for cavernous sinus meningiomas: a prospective study. Neurosurgery 2004;55:1068-75.

6. Cusimano MD, Sekhar LN, Sen CN, Pomonis S, Wright DC, et al. The results of surgery for benign tumors of the cavernous sinus. Neurosurgery 1995;37:1-9; discussion 9-10.

7. DeMonte F, Smith HK, al-Mefty O. Outcome of aggressive removal of cavernous sinus meningiomas. J Neurosurg 1994;81:245-51.

8. O'Sullivan MG, van Loveren HR, Tew JM Jr. The surgical resectability of meningiomas of the cavernous sinus. Neurosurgery 1997;40:238-44; discussion 245-7.

9. Saberi H, Meybodi AT, Rezai AS. Levine-Sekhar grading system for prediction of the extent of resection of cranial base meningiomas revisited: study of 124 cases. Neurosurg Rev 2006;29:138-44.

10. Alfieri A, Jho HD, Schettino R, Tschabitscher M. Endoscopic endonasal approach to the pterygopalatine fossa: anatomic study. Neurosurgery 2003;52:374-8; discussion 378-80.

11. Cavallo LM, Messina A, Gardner P, Esposito F, Kassam AB, et al. Extended endoscopic endonasal approach to the pterygopalatine fossa: anatomical study and clinical considerations. Neurosurg Focus 2005;19:E5.

12. Solari D, Magro F, Cappabianca P, Cavallo LM, Samii A, et al. Anatomical study of the pterygopalatine fossa using an endoscopic endonasal approach: spatial relations and distances between surgical landmarks. J Neurosurg 2007;106:157-63.

13. Kasemsiri P, Solares CA, Carrau RL, Prosser JD, Prevedello DM, et al. Endoscopic endonasal transpterygoid approaches: anatomical landmarks for planning the surgical corridor. Laryngoscope 2013;123:811-5.

14. Kassam AB, Prevedello DM, Carrau RL, Snyderman CH, Gardner P, et al. The front door to meckel's cave: an anteromedial corridor via expanded endoscopic endonasal approach- technical considerations and clinical series. Neurosurgery 2009;64:ons71-82; discussion ons82-3.

15. Cappabianca P, Cavallo LM, Esposito F, de Divitiis O, Messina A, et al. Extended endoscopic endonasal approach to the midline skull base: the evolving role of transsphenoidal surgery. In: Pickard JD, Akalan N, Di Rocco C, Dolenc VV, Antunes JL, Mooij JJA, Schramm J, Sindou M, editors. Advances and Technical Standards in Neurosurgery. Vienna: Springer; 2008. pp. 151-99.

16. Cavallo LM, de Divitiis O, Aydin S, Messina A, Esposito F, et al. Extended endoscopic endonasal transsphenoidal approach to the suprasellar area: anatomic considerations--part 1. Neurosurgery 2007;61:24-33; discussion 33-4.

17. Jouanneau E, Simon E, Jacquesson T, Sindou M, Tringali S, et al. The endoscopic endonasal approach to the Meckel's cave tumors: surgical technique and indications. World Neurosurg 2014;82:S155-61.

18. Zhang QH, Guo HC, Kong F, Chen G, Liang JT, et al. Resection of the intracavernous sinus tumors using a purely endoscopic endonasal approach. J Craniofac Surg 2014;25:295-302.

19. Yano S, Hide T, Shinojima N, Hasegawa Y, Kawano T, et al. Endoscopic endonasal skull base approach for parasellar lesions: initial experiences, results, efficacy, and complications. Surg Neurol Int 2014;5:51.

20. Abdel-Aziz KM, Froelich SC, Dagnew E, Jean W, Breneman JC, et al. Large sphenoid wing meningiomas involving the cavernous sinus: conservative surgical strategies for better functional outcomes. Neurosurgery 2004;54:1375-83; discussion 1383-4.

21. Dufour H, Muracciole X, Métellus P, Régis J, Chinot O, et al. Long-term tumor control and functional outcome in patients with cavernous sinus meningiomas treated by radiotherapy with or without previous surgery: is there an alternative to aggressive tumor removal? Neurosurgery 2001;48:285-94; discussion 294-6.

22. Sindou M, Wydh E, Jouanneau E, Nebbal M, Lieutaud T. Long-term follow-up of meningiomas of the cavernous sinus after surgical treatment alone. J Neurosurg 2007;107:937-44.

23. Al-mefty O, Smith RR. Surgery of tumors invading the cavernous sinus. Surgical Neurology 1988;30:370-81.

24. Diao Y, Liang L, Yu C, Zhang M. Is there an identifiable intact medial wall of the cavernous sinus? Macro- and microscopic anatomical study using sheet plastination. Neurosurgery 2013;73:ons106-9; discussion ons110.

25. Dallan I, Castelnuovo P, de Notaris M, Sellari-Franceschini S, Lenzi R, et al. Endoscopic endonasal anatomy of superior orbital fissure and orbital apex regions: critical considerations for clinical applications. Eur Arch Otorhinolaryngol 2013;270:1643-9.

26. Shaffrey ME, Dolenc VV, Lanzino G, Wolcott W, Shaffrey CI. Invasion of the internal carotid artery by cavernous sinus meningiomas. Surg Neurol 1999;52:167-71.

27. Messerer M, De Battista JC, Raverot G, Kassis S, Dubourg J, et al. Evidence of improved surgical outcome following endoscopy for nonfunctioning pituitary adenoma removal. Neurosurg Focus 2011;30:E11. 
28. Sivakumar W, Barkhoudarian G, Lobo BM, Zhang X, Zhao F, et al. Strategy and technique of endonasal endoscopic bony decompression and selective tumor removal in symptomatic skull base meningiomas of the cavernous sinus and Meckel's Cave. World Neurosurg 2019;131:e12-22.

29. Berhouma M, Jacquesson T, Abouaf L, Vighetto A, Jouanneau E. Endoscopic endonasal optic nerve and orbital apex decompression for nontraumatic optic neuropathy: surgical nuances and review of the literature. Neurosurg Focus 2014;37:E19.

30. Akutsu H, Kreutzer J, Fahlbusch R, Buchfelder M. Transsphenoidal decompression of the sellar floor for cavernous sinus meningiomas: experience with 21 patients. Neurosurgery 2009;65:54-62; discussion 62.

31. Graillon T, Fuentes S, Metellus P, Adetchessi T, Gras R, et al. Limited endoscopic transsphenoidal approach for cavernous sinus biopsy: illustration of 3 cases and discussion. Neurochirurgie 2014;60:42-7.

32. Lobo B, Zhang X, Barkhoudarian G, Griffiths CF, Kelly DF. Endonasal endoscopic management of parasellar and cavernous sinus meningiomas. Neurosurg Clin N Am 2015;26:389-401.

33. Khan OH, Anand VK, Schwartz TH. Endoscopic endonasal resection of skull base meningiomas: the significance of a "cortical cuff" and brain edema compared with careful case selection and surgical experience in predicting morbidity and extent of resection. Neurosurg Focus 2014;37:E7.

34. Zhang Q, Wang Z, Guo H, Yan B, Wang Z, et al. Direct transcavernous sinus approach for endoscopic endonasal resection of intracavernous sinus tumors. World Neurosurg 2019;128:e478-87.

35. Koutourousiou M, Vaz Guimaraes Filho F, Fernandez-Miranda JC, Wang EW, Stefko ST, et al. Endoscopic endonasal surgery for tumors of the cavernous sinus: a series of 234 patients. World Neurosurg 2017;103:713-32.

36. Liu HS, Di X. Endoscopic endonasal surgery for biopsy of cavernous sinus lesions. Minim Invasive Neurosurg 2009;52:69-73.

37. Leroy HA, Tuleasca C, Reyns N, Levivier M. Radiosurgery and fractionated radiotherapy for cavernous sinus meningioma: a systematic review and meta-analysis. Acta Neurochir (Wien) 2018;160:2367-78.

38. Metellus P, Regis J, Muracciole X, Fuentes S, Dufour H, et al. Evaluation of fractionated radiotherapy and gamma knife radiosurgery in cavernous sinus meningiomas: treatment strategy. Neurosurgery 2005;57:873-86; discussion 873-86.

39. Correa SF, Marta GN, Teixeira MJ. Neurosymptomatic carvenous sinus meningioma: a 15-years experience with fractionated stereotactic radiotherapy and radiosurgery. Radiat Oncol 2014;9:27.

40. Han J, Girvigian MR, Chen JC, Miller MJ, Lodin K, et al. A comparative study of stereotactic radiosurgery, hypofractionated, and fractionated stereotactic radiotherapy in the treatment of skull base meningioma. Am J Clin Oncol 2014;37:255-60.

41. Roche PH, Régis J, Dufour H, Fournier HD, Delsanti C, et al. Gamma knife radiosurgery in the management of cavernous sinus meningiomas. J Neurosurg 2000;93:68-73.

42. Lee JY, Niranjan A, McInerney J, Kondziolka D, Flickinger JC, et al. Stereotactic radiosurgery providing long-term tumor control of cavernous sinus meningiomas. J Neurosurg 2002;97:65-72.

43. Iwai Y, Yamanaka K, Ishiguro T. Gamma knife radiosurgery for the treatment of cavernous sinus meningiomas. Neurosurgery 2003;52:517-24; discussion 523-4.

44. dos Santos MA, de Salcedo JB, Gutiérrez Diaz JA, Calvo FA, Samblás J, et al. Long-term outcomes of stereotactic radiosurgery for treatment of cavernous sinus meningiomas. Int J Radiat Oncol Biol Phys 2011;81:1436-41.

45. Pollock BE, Stafford SL. Results of stereotactic radiosurgery for patients with imaging defined cavernous sinus meningiomas. Int J Radiat Oncol Biol Phys 2005;62:1427-31.

46. Pollock BE, Stafford SL, Link MJ. Stereotactic radiosurgery of intracranial meningiomas. Neurosurg Clin N Am 2013;24:499-507.

47. Oya S, Kim SH, Sade B, Lee JH. The natural history of intracranial meningiomas. J Neurosurg 2011;114:1250-6.

48. Rowe JG, Walton L, Vaughan P, Malik I, Radatz M, et al. Radiosurgical planning of meningiomas: compromises with conformity. Stereotact Funct Neurosurg 2004;82:169-74.

49. DiBiase SJ, Kwok Y, Yovino S, Arena C, Naqvi S, et al. Factors predicting local tumor control after gamma knife stereotactic radiosurgery for benign intracranial meningiomas. Int J Radiat Oncol Biol Phys 2004;60:1515-9.

50. Rogers L, Jensen R, Perry A. Chasing your dural tail: factors predicting local tumor control after gamma knife stereotactic radiosurgery for benign intracranial meningiomas: In regard to DiBiase et al. (Int J Radiat Oncol Biol Phys 2004;60:1515-1519). Int J Radiat Oncol Biol Phys 2005;62:616-8; author reply 618-9.

51. Fariselli L, Biroli A, Signorelli A, Broggi M, Marchetti M, et al. The cavernous sinus meningiomas' dilemma: surgery or stereotactic radiosurgery? Rep Pract Oncol Radiother 2016;21:379-85.

52. Hasegawa T, Kida Y, Yoshimoto M, Koike J, Iizuka H, et al. Long-term outcomes of Gamma Knife surgery for cavernous sinus meningioma. J Neurosurg 2007;107:745-51.

53. Park KJ, Kano H, Iyer A, Liu X, Tonetti DA, et al. Gamma Knife stereotactic radiosurgery for cavernous sinus meningioma: long-term follow-up in 200 patients. J Neurosurg 2018;1-10.

54. Rueß D, Fritsche F, Grau S, Treuer H, Hoevels M, et al. Stereotactic radiosurgery of cavernous sinus meningiomas. J Neurol Surg B Skull Base 2020;81:158-64.

55. Sughrue ME, Rutkowski MJ, Aranda D, Barani IJ, McDermott MW, et al. Factors affecting outcome following treatment of patients with cavernous sinus meningiomas. J Neurosurg 2010;113:1087-92.

56. Kano H, Park KJ, Kondziolka D, Iyer A, Liu X, et al. Does prior microsurgery improve or worsen the outcomes of stereotactic radiosurgery for cavernous sinus meningiomas? Neurosurgery 2013;73:401-10.

57. Shin M, Kurita H, Sasaki T, Kawamoto S, Tago M, et al. Analysis of treatment outcome after stereotactic radiosurgery for cavernous sinus meningiomas. J Neurosurg 2001;95:435-9. 
58. Cossu G, Levivier M, Daniel RT, Messerer M. The role of mifepristone in meningiomas management: a systematic review of the literature. Biomed Res Int 2015;2015:267831.

59. Lou E, Sumrall AL, Turner S, Peters KB, Desjardins A, et al. Bevacizumab therapy for adults with recurrent/progressive meningioma: a retrospective series. J Neurooncol 2012;109:63-70. 